\title{
Brayton-Moser Passivity Based Controller for Electric Vehicle Battery Charger
}

\author{
Kumari SHIPRA, Rakesh MAURYA, and Shambhu N. SHARMA
}

\begin{abstract}
In this paper Brayton-Moser passivity-based control (BM-PBC) methodology is developed for an on-board battery charger for plug-in electric vehicles(PHEVs). The main features of this electric vehicle (EV) charger include improved power quality, reduced filter size and voltage stress across the switches and fast dynamic response. In this paper, a dynamic model of the three-level (TL) boost power factor correction (PFC) converter is developed using the Brayton-Moser formulation. Then, the Brayton-Moser based control technique is designed by injecting a virtual resistor in series with the input inductor. Further, the stability analysis of the proposed controller is also carried out using energy balance approach. To improve the dynamic performance and reduce the steady state error, a PI controller is integrated with the aforesaid controller. Therefore, the controller comprises of BM-PBC and the PI controller is implemented for the TL boost PFC converter as a battery charger and its performances are investigated under various operating modes with the help of MATLAB/Simulink. Furthermore, power quality of charger is assessed by monitoring source current total harmonic distortion (THD) under different operating conditions. It is also observed that the proposed system provides THD less than $5 \%$ in source current which satisfies IEC 61000-3-2 Class C standard. The performance of the aforesaid controller is also compared with the conventional PI controller. In order to validate the proposed controller, a prototype model of same specifications is tested in hardware in loop and obtained test results are also presented.
\end{abstract}

Index Terms-Brayton-Moser, mathematical modelling, passivity-based control, three-level boost converter.

\section{NOMENCLATURE}

$C_{1}, C_{2}, C \quad$ Capacitor, $\mu \mathrm{F}$.

$E(t) \quad$ Rectified input voltage, $\mathrm{V}$.

$E_{\mathrm{f}} \quad$ Energy function.

$\dot{E}_{\mathrm{f}} \quad$ Derivative of $E_{\mathrm{f}}$.

$G_{\mathrm{i}} \quad$ Parallel damping injection.

$I_{\mathrm{d}} \quad$ Desired current, A.

$i_{L} \quad$ Inductor current, A.

$i_{L \mathrm{D}} \quad$ Desired average inductor current, A.

Manuscript received February 29, 2020; revised September 18, 2020; accepted December 23, 2020. Date of publication March 30, 2021; date of current version March 12, 2021.

All authors are with the Department of Electrical Engineering, Sardar Vallabhbhai National Institute of Technology, Surat 395007, India (e-mail: kumarishipra2005@gmail.com; rmaurya@eed.svnit.ac.in; sns@eed.svnit.ac.in). Digital Object Identifier 10.24295/CPSSTPEA.2021.00004

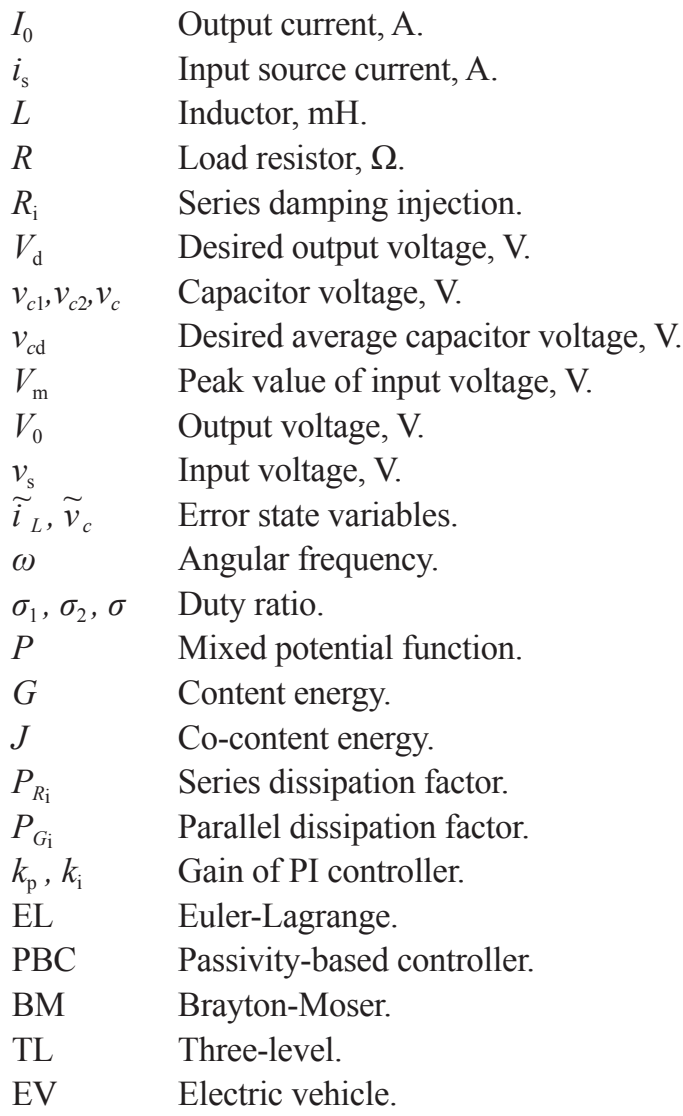

\section{INTRODUCTION}

DLUG-in electric vehicles (PHEVs) are one of the sustainable mean of transportation as compared to internal combustion engine based automobile due to various advantages such as low transportation cost, low maintenance, high efficiency, and environmentally friendly [1], [2]. For successful implementation of PHEVs, the EVs charger is playing key role for charging EVs battery and therefore efficient battery charger along with improved power quality features, are the main requirements in view of large penetration of PHEVs in electrical power grid. According to guidelines prescribed by IEEE STD 519-2014 and IEC 61000-3-2, the power factor should be more than 0.9 and total harmonic distortion (THD)in source current should be less than 5\% for any single phase system [3]. In view of aforesaid regulation, several EVs charger as power factor correction (PFC) converters are reported in literature whose operations mainly governed by good design of power circuit 
and its controller. The boost PFC converter is one of converter which has been extensively used as PFC in design of general purpose power supply because of simple circuit, allows lowdistorted input currents along with unity power factor [4], [5]. However, it brings large switching stresses and switching losses which yields low efficiency. Hence, a three-level (TL) boost PFC converter topology has been proposed to reduce stress across the switch as well as filter size by adding additional capacitor, diode and switch in existing circuit [6], [7].

Design efficient controller requires accurate mathematical modelling of the system. In the mid-seventies, the Middlebrook and Ćuk was first offered a modelling of the switched regulated DC-DC power converter [8]. The Euler-Lagrange (EL) formulation of a boost, a buck-boost and a fly-back converter are discussed in [9],[10]. In [11], the Lagrangian dynamics approach is used for modelling of a Ćuk, a threephase boost and a coupled-inductor Ćuk converters. The EL based modelling approach of DC-DC power converter with non-ideal switches including parasitic is presented in [12]. The EL modelling of the multivariable of the boost converter constituted by the cascaded connection is also discussed in [13]. There is drawback of the EL as it is not suitable for non-ideal switches, diodes, transformers, and isolation transformers etc. In [13], the Hamiltonian dynamics approach are discussed for modelling of boost, Ćuk, fly-back for ideal switches and also for non-ideal switches and diodes. A mathematical formulation for switched electrical networks has been discussed by Brayton and Moser (1964) in [9]. In this formulation, the current and voltage are obtained variables, so controller can directly use obtained variables as a measured variable. This is also suitable for non-ideal switches, diodes and transformers etc.

There are various linear and non-linear control methodologies reported in literature which is designed to control the switched electrical system against dynamic variation [14][18]. Generally, linear controllers like (P, PI, PID) have been widely used to control the converters as discussed in[14], but these controllers have highly unpredictable tuning problem of controller parameters. So, these controllers are not suitable and user friendly. Recently, many non-linear controllers such as sliding mode control, fuzzy logic control (FLC) etc. are reported in [18], [19]. Several control techniques have been proposed for controlling the switched electrical system to charge EVs battery [20]-[22]. A conventional PI control technique is highly used as it is simple to implement [20]. In [21], the approximate rule based FLC technique has been implemented to achieve battery charging and discharging applications. A non-linear model predictive controller for battery charging application is discussed in [22].

Recently, power shaping based passivity-based controllers (PBCs) have been widely used in several research areas such as robot arms, induction motors, switched power converters etc.[23]. In order to achieve equilibrium stability, a virtual resistor is added as a damping factor in power shaping passivity based controller. So that the system becomes passive (an increase of the storage energy should be less than the rate of flow of energy into the system) against disturbances. The EL and the port controlled Hamiltonian based passivity control technique are very powerful and robust for switched electrical system[13], [24]-[27]. The passivity-based control theory is implemented to bidirectional buck-boost converter for battery charging application in [28]. An adaptive passivity based control design technique for battery hybrid power source has been proposed in [29]. A new concept of passivity-based controller known as Brayton-Moser has overcome the problem of selection of damping factor unlike EL based PBC controller. Additionally, the Brayton-Moser based controller requires controlled variables which are directly expressed in physical measurable variables like current and voltage in switched electrical network while the EL and the Hamiltonian have physical variables charge or flux to control current and voltage of system. The concept of the Brayton-Moser based controller for switched electrical systems is reported in [30]-[32].

In this paper, a Brayton-Moser passivity-based controller has been developed for an on-board battery charger using the TL boost converter to achieve well-regulated voltage and current along with nearly unity power factor operation while charging EV battery. The TL boost converter has an additional switch, diode, capacitor and operation of its switches are shifted by $180^{\circ}$ out of phase. Due to these additional elements and its interleaved operation, the switch stress as well as filter size are reduced considerably.

This paper is structured in the following manner. Section I describes the brief introduction of the TL boost converter, PFC and PBCs. The mathematical modelling of the TL boost converter using the Brayton-Moser formulation is carried out in Section II. It also covers brief description of circuit and its operational modes under different switching states. The Brayton-Moser equation for electrical circuit is also review in Section II. Section III narrates the control topology of the Brayton-Moser based PBC for the TL boost converter along with analysis of stability. Section IV presents simulation study and its test results of the proposed converter for battery load constant current (CC) and constant voltage (CV) mode. Concluding remarks are given in Section V.

\section{Mathematical Modeling of the TL Boost PFC CONVERTER}

A schematic diagram of TL boost PFC converter with the Brayton-Moser passivity-based controller is depicted in Fig. 1. The proposed system is employed for charging the electric vehicle battery under $\mathrm{CC}$ and $\mathrm{CV}$ modes. The detailed mathematical analysis and operation are carried out in the following subsections.

\section{A. Topology}

The power circuit of TL boost PFC converter along with the BM-PBC is presented in Fig. 1. It consists of a single-phase diode bridge rectifier (DBR), TL boost converter, battery load 


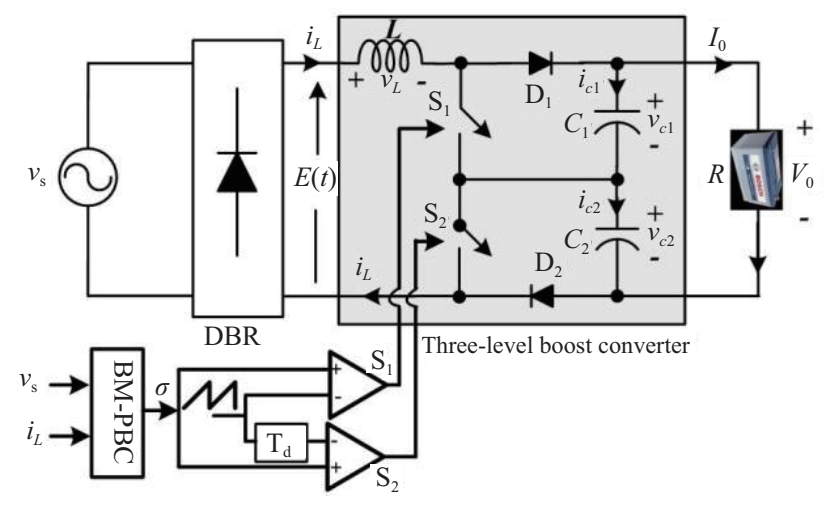

Fig. 1. Schematic diagram of a TL boost PFC converter.

and a PBC as an on-board battery charger for $\mathrm{CC} / \mathrm{CV}$ charging of EV battery. The proposed TL boost converter is derived from conventional boost DC-DC converter by splitting output capacitor $(C)$ into output capacitors $\left(C_{1}, C_{2}\right)$, diode (D) into diodes $\left(\mathrm{D}_{1}, \mathrm{D}_{2}\right)$ and switch $(\mathrm{S})$ into switches $\left(\mathrm{S}_{1}, \mathrm{~S}_{2}\right)$ as shown in Fig. 1.

A single-phase AC supply is connected to a DBR to get rectified voltage which act as input voltage source for TL boost converter. The switches are operated in interleaved manner to achieve reduced ripple contents in passive elements. A $\mathrm{BM}-\mathrm{PBC}$ methodology is applied to control the closed loop operation of converter as shown in Fig. 1.

\section{B. Operational Modes}

Prior to steady-state analysis of the proposed converter, few assumptions are made such as ideal passive elements and switching devices. It is also assumed that for a given sampling time $\left(T_{\mathrm{s}}\right)$, supply voltage $\left(v_{\mathrm{s}}\right)$ remains constant. The duty cycle $\sigma(t)$ varies in each sample either $\sigma(t)<0.5$ or $\sigma(t)>0.5$ during each sampling interval as instantaneous value of rectified voltage $E(t)$, keeps on changing. For one sampling time $T_{\mathrm{s}}$, the switch is on for $\sigma T_{\mathrm{s}}$ and off for $(1-\sigma) T_{\mathrm{s}}$ period as depicted in Fig. 2. Depending upon the switching state of switches $\left(\mathrm{S}_{1}, \mathrm{~S}_{2}\right)$, four operating modes are identified which repeat several times in one cycle of the line frequency (i.e., $50 \mathrm{~Hz}$ ). The waveforms of voltage and current of circuit elements are depicted in Fig. 2.

\section{The Brayton-Moser Equations for Electrical Circuit}

According to the Brayton-Moser [33], the differential equations representing dynamical behaviour of non-linear electrical circuits is given below:

$$
\left\{\begin{array}{l}
-L \frac{\mathrm{d} i_{L}}{\mathrm{~d} t}=\frac{\partial P}{\partial i_{L}}\left(i_{L}, v_{c}\right) \\
C \frac{\mathrm{d} v_{c}}{\mathrm{~d} t}=\frac{\partial P}{\partial v_{c}}\left(i_{L}, v_{c}\right)
\end{array}\right.
$$

where $i_{L} \in R^{\prime \prime}$ is the input inductor currents, $v_{c} \in R^{m}$ is the capacitor voltages and $P: R^{n \times m}$ is mixed-potential function.

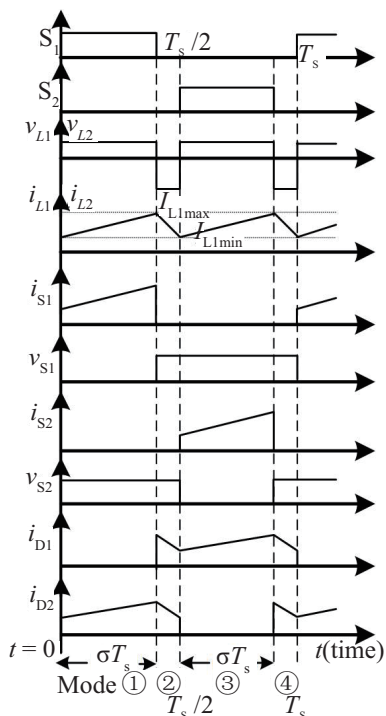

(a)

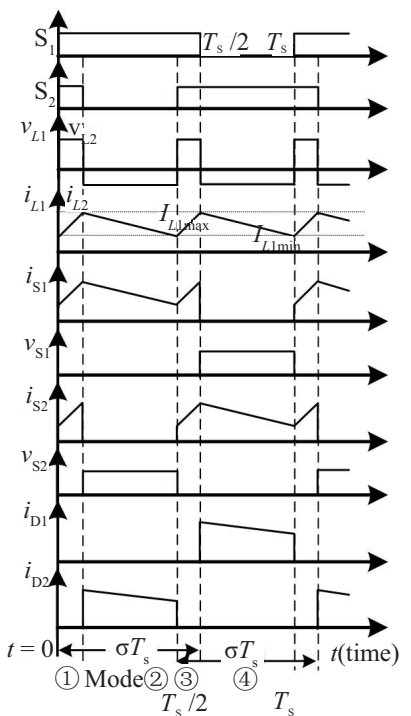

(b)
Fig. 2. Switching waveform of the TL boost converter over one switching cycle for (a) and (b) .

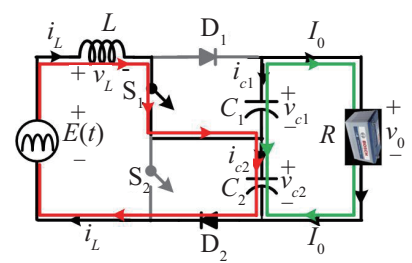

(a)

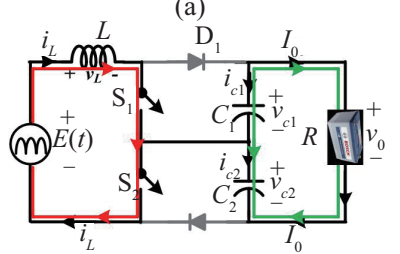

(c)

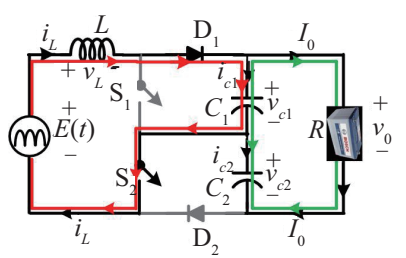

(b)

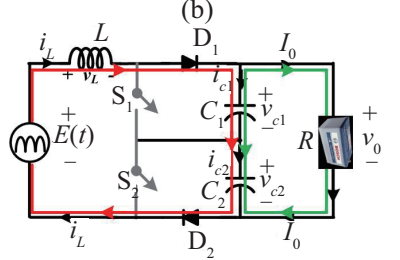

(d)
Fig. 3. Equivalent circuit of the TL boost converter under various operating modes: (a) mode 1, (b) mode 2, (c) mode 3 and (d) mode 4.

The matrices $L\left(i_{L}\right) \in R^{n \times n}$ and $C\left(v_{c}\right) \in R^{m \times m}$ are the inductance and capacitance matrices respectively. The mixed-potential function $P$ is: $\mathrm{d} P=\mathrm{d} G-\mathrm{d} J$, where $G$ and $J$ are content and co-content energy function respectively, $\mathrm{d} G=\left\langle i_{L}, d v_{c}>\right.$ and $\mathrm{d} J=<v_{c}, \mathrm{~d} i_{L}>$.

\section{Mathematical Modelling of the TL Boost Converter}

In this section, the mathematical modelling of the TL boost converter has been carried out using the Brayton-Moser formulation as given in (1). So, first we should obtain the mixed potential function (MPF) for all four possible positions of switches $\left(\sigma_{1}, \sigma_{2}\right)$ such as $(1,0),(0,1),(1,1)$ and $(0,0)$ as given below:

Mode 1: At switch position $(1,0)$, means switch $\left(S_{1}\right)$ is conducting and switch $\left(\mathrm{S}_{2}\right)$ is off as shown in Fig. 3(a) and correspondingly duty functions are $\sigma_{1}=1$ and $\sigma_{2}=0$. Hence, the MPF for switch position $(1,0)$ is given below: 


$$
\begin{gathered}
G\left(i_{L}, v_{c 1}, v_{c 2}\right)=-E i_{L}+\frac{1}{2} i_{L} v_{c 2}, \\
J\left(i_{L}, v_{c 1}, v_{c 2}\right)=\frac{1}{2 R}\left(v_{c 1}+v_{c 2}\right)^{2}-\frac{1}{2} i_{L} v_{c 2}, \\
P^{(1,0)}\left(i_{L}, v_{c 1}, v_{c 2}\right)=-E i_{L}+i_{L} v_{c 2}-\frac{1}{2 R}\left(v_{c 1}+v_{c 2}\right)^{2}
\end{gathered}
$$

Mode 2: In this mode, switches are at position $(0,1)$, when switch $\left(\mathrm{S}_{1}\right)$ is off and switch $\left(\mathrm{S}_{2}\right)$ is conducting and the diodes $\left(\mathrm{D}_{1}, \mathrm{D}_{2}\right)$ are in forward and reverse biased respectively as shown in Fig. 3(b). In this case the duty functions are $\sigma_{1}=0$ and $\sigma_{2}=1$. Hence, MPF for switch position $(0,1)$ is given below:

$$
\begin{gathered}
G\left(i_{L}, v_{c 1}, v_{c 2}\right)=-E i_{L}+\frac{1}{2} i_{L} v_{c 1}, \\
J\left(i_{L}, v_{c 1}, v_{c 2}\right)=\frac{1}{2 R}\left(v_{c 1}+v_{c 2}\right)^{2}-\frac{1}{2} i_{L} v_{c 1}, \\
P^{(0,1)}\left(i_{L}, v_{c 1}, v_{c 2}\right)=-E i_{L}+i_{L} v_{c 1}-\frac{1}{2 R}\left(v_{c 1}+v_{c 2}\right)^{2} .
\end{gathered}
$$

Mode 3: In this case, both the switches $\left(\mathrm{S}_{1}, \mathrm{~S}_{2}\right)$ are conducting and diodes $\left(\mathrm{D}_{1}, \mathrm{D}_{2}\right)$ are reverse biased as shown in Fig. 3(c) and correspondingly duty functions are $\sigma_{1}=\sigma_{2}=1$. Hence, MPF for switch position $(1,1)$ is given below:

$$
\begin{gathered}
G\left(i_{L}, v_{c 1}, v_{c 2}\right)=-E i_{L}, \\
J\left(i_{L}, v_{c 1}, v_{c 2}\right)=\frac{1}{2 R}\left(v_{c 1}+v_{c 2}\right)^{2}, \\
P^{(1,1)}\left(i_{L}, v_{c 1}, v_{c 2}\right)=-E i_{L}-\frac{1}{2 R}\left(v_{c 1}+v_{c 2}\right)^{2} .
\end{gathered}
$$

Mode 4: In this case, both switches are non-conducting and diodes $\left(\mathrm{D}_{1}, \mathrm{D}_{2}\right)$ are forward biased as shown in Fig. 3(d) and correspondingly duty functions are $\sigma_{1}=\sigma_{2}=0$. The MPF for switch position $(0,0)$ is given below:

$$
\begin{gathered}
G\left(i_{L}, v_{c 1}, v_{c 2}\right)=-E i_{L}+\frac{1}{2} i_{L}\left(v_{c 1}+v_{c 2}\right), \\
J\left(i_{L}, v_{c 1}, v_{c 2}\right)=\frac{1}{2 R}\left(v_{c 1}+v_{c 2}\right)^{2}-\frac{1}{2} i_{L}\left(v_{c 1}+v_{c 2}\right), \\
P^{(0,0)}\left(i_{L}, v_{c 1}, v_{c 2}\right)=-E i_{L}+i_{L}\left(v_{c 1}+v_{c 2}\right)-\frac{1}{2 R}\left(v_{c 1}+v_{c 2}\right)^{2} .
\end{gathered}
$$

Now, above written MPFs for all four possible switching positions can be re-written in terms of switching functions $\left(\sigma_{1}, \sigma_{2}\right)$ as given below:

$$
\begin{aligned}
P^{\left(\sigma_{1}, \sigma_{2}\right)}\left(i_{L}, v_{c 1}, v_{c 2}\right)= & -E i_{L}+\left(1-\sigma_{1}\right) i_{L} v_{c 1} \\
& +\left(1-\sigma_{2}\right) i_{L} v_{c 2}-\frac{1}{2 R}\left(v_{c 1}+v_{c 2}\right)^{2},
\end{aligned}
$$

where $P^{(\sigma 1, \sigma 2)}\left(i_{L}, v_{c 1}, v_{c 2}\right)$ is the MPF for the switch position $\left(\sigma_{1}\right.$, $\sigma_{2}$ ). From (1) and (2), partial differentiation of the above MPF is done with respect to each variable and obtain following state equations:

$-L \frac{\mathrm{d} i_{L}}{\mathrm{~d} t}=\frac{\partial P^{\left(\sigma_{1}, \sigma_{2}\right)}}{\partial i_{L}}\left(i_{L}, v_{c 1}, v_{c 2}\right)=-E+\left(1-\sigma_{1}\right) v_{c 1}+\left(1-\sigma_{2}\right) v_{c 2}$,
$C_{1} \frac{\mathrm{d} v_{c 1}}{\mathrm{~d} t}=\frac{\partial P^{\left(\sigma_{1}, \sigma_{2}\right)}}{\partial v_{c 1}}\left(i_{L}, v_{c 1}, v_{c 2}\right)=\left(1-\sigma_{1}\right) i_{L}-\frac{1}{R}\left(v_{c 1}+v_{c 2}\right)$,

$C_{2} \frac{\mathrm{d} v_{c 2}}{\mathrm{~d} t}=\frac{\partial P^{\left(\sigma_{1}, \sigma_{2}\right)}}{\partial v_{c 2}}\left(i_{L}, v_{c 1}, v_{c 2}\right)=\left(1-\sigma_{2}\right) i_{L}-\frac{1}{R}\left(v_{c 1}+v_{c 2}\right)$.

Assuming $i_{L}, v_{c 1}$ and $v_{c 2}$ as state variables, (3)-(5) are rearranged in the matrix-form as given below:

$$
\left[\begin{array}{l}
\dot{i}_{L} \\
\dot{v}_{c 1} \\
\dot{v}_{c 2}
\end{array}\right]=\left[\begin{array}{ccc}
0 & -\frac{\left(1-\sigma_{1}\right)}{L} & -\frac{\left(1-\sigma_{2}\right)}{L} \\
\frac{\left(1-\sigma_{1}\right)}{C_{1}} & -\frac{1}{R C_{1}} & -\frac{1}{R C_{2}} \\
\frac{\left(1-\sigma_{2}\right)}{C_{2}} & -\frac{1}{R C_{1}} & -\frac{1}{R C_{2}}
\end{array}\right]\left[\begin{array}{l}
i_{L} \\
v_{c 1} \\
v_{c 2}
\end{array}\right]+\left[\begin{array}{l}
\frac{1}{L} \\
0 \\
0
\end{array}\right] E .
$$

\section{BM Passivity Based Controller}

In this section, the BM-PBC based controller is developed for the TL boost PFC converter to charge the EVs battery under $\mathrm{CC}$ and $\mathrm{CV}$ modes along with improved power factor features at $\mathrm{AC}$ supply side.

\section{A. BM Model of the TL Boost PFC Converter}

In order to control the TL boost converter, the duty ratio of both switches $\left(\mathrm{S}_{1}, \mathrm{~S}_{2}\right)$ are same i.e., $\sigma_{1}=\sigma_{2}=\sigma$, but phaseshifted by $180^{\circ}$. The measured and controlled variables of the proposed system is output voltage $V_{0}$ which is average of $v_{\mathrm{c}}$. So, the new average state variables can be defined as $v_{c}=v_{c 1}+$ $v_{c 2}$. Let $C_{1}=C_{2}=2 C$. The new equivalent state-space equation of the proposed system with new state variables $\left(i_{L}, v_{c}\right)$ as derived by the Brayton-Moser formulations is given as:

$$
\left[\begin{array}{c}
L \frac{\mathrm{d} i_{L}}{\mathrm{~d} t} \\
C \frac{\mathrm{d} v_{c}}{\mathrm{~d} t}
\end{array}\right]=\left[\begin{array}{cc}
0 & -(1-\sigma) \\
(1-\sigma) & -\frac{1}{R}
\end{array}\right]\left[\begin{array}{l}
i_{L} \\
v_{c}
\end{array}\right]+\left[\begin{array}{l}
1 \\
0
\end{array}\right] E .
$$

The above average state-space equation can be written in the $\mathrm{BM}$ form as given below:

$$
\left\{\begin{array}{l}
-L \frac{\mathrm{d} i_{L}}{\mathrm{~d} t}=\frac{\partial P}{\partial i_{L}}\left(i_{L}, v_{c}\right) \\
C \frac{\mathrm{d} v_{c}}{\mathrm{~d} t}=\frac{\partial P}{\partial v_{c}}\left(i_{L}, v_{c}\right)
\end{array} .\right.
$$

The desired trajectories of the average state variables are as follow:

$$
\left\{\begin{array}{l}
-L \frac{\mathrm{d} i_{L \mathrm{~d}}}{\mathrm{~d} t}=\frac{\partial P}{\partial i_{L \mathrm{~d}}}\left(i_{L \mathrm{~d}}, v_{c \mathrm{~d}}\right) \\
C \frac{\mathrm{d} v_{c \mathrm{~d}}}{\mathrm{~d} t}=\frac{\partial P}{\partial v_{c \mathrm{~d}}}\left(i_{L \mathrm{~d}}, v_{c \mathrm{~d}}\right)
\end{array} .\right.
$$


where $i_{L \mathrm{~d}}, v_{c \mathrm{~d}}$, are the desired trajectory for the average inductor current and average output voltage for one switching cycle respectively. The error trajectory of the state variables as $\widetilde{i}_{L}=$ $i_{L}-i_{L \mathrm{~d}}$ and $\widetilde{v}_{c}=v_{c}-v_{c \mathrm{~d}}$, are obtained from (7) and (8). The error dynamics are described as given below:

$$
\left\{\begin{array}{l}
-L \frac{\mathrm{d} \tilde{i}_{L}}{\mathrm{~d} t}=\frac{\partial P}{\partial i_{L}}\left(i_{L}, v_{c}\right)-\frac{\partial P}{\partial i_{L \mathrm{~d}}}\left(i_{L \mathrm{~d}}, v_{c \mathrm{~d}}\right) \\
C \frac{\mathrm{d} \tilde{v}_{c}}{\mathrm{~d} t}=\frac{\partial P}{\partial v_{c}}\left(i_{L}, v_{c}\right)-\frac{\partial P}{\partial v_{c \mathrm{~d}}}\left(i_{L \mathrm{~d}}, v_{c \mathrm{~d}}\right)
\end{array} .\right.
$$

A series and parallel damping dissipation factors are added to the above error dynamics equations which yields below:

$$
\left\{\begin{array}{l}
-L \frac{\mathrm{d} \tilde{i}_{L}}{\mathrm{~d} t}=\frac{\partial P}{\partial \tilde{i}_{L}}\left(\tilde{i}_{L}, \tilde{v}_{c}\right)+\frac{\partial P_{R_{\mathrm{i}}}}{\partial \tilde{i}_{L}}\left(\tilde{i}_{L}, \tilde{v}_{c}\right) \\
C \frac{\tilde{v}_{c}}{\mathrm{~d} t}=\frac{\partial P}{\partial \tilde{v}_{c}}\left(\tilde{i}_{L}, \tilde{v}_{c}\right)+\frac{\partial P_{G_{\mathrm{i}}}}{\left.\partial \tilde{i}_{c}, \tilde{v}_{c}\right)}
\end{array}\right.
$$

where $P_{R_{\mathrm{i}}}=R_{\mathrm{i}} \widetilde{i}_{L}^{2} / 2$ and $P_{G_{\mathrm{i}}}=G_{\mathrm{i}} \tilde{v}_{c}^{2} / 2$ are the injected dissipation terms. $R_{\mathrm{i}}$ and $G_{\mathrm{i}}$ are the injected series damping with the inductor and injected parallel damping with the capacitor respectively.

\section{B. Stability Analysis}

Let a positive definite energy function $E_{\mathrm{f}}$ of the proposed system is created as:

$$
E_{\mathrm{f}}=\frac{1}{2} \tilde{L} \tilde{i}_{L}^{2}+\frac{1}{2}{\tilde{C v_{c}}}^{2}
$$

From (11), $E_{\mathrm{f}}=0$ only when $\widetilde{i}_{L}=0$ and $\widetilde{v}_{c}=0$ or else $E_{f}>0$ The derivative of $E_{\mathrm{f}}$, is given below:

$$
\dot{E}_{\mathrm{f}}=\dot{L \dot{i}_{L}} \cdot \tilde{i}_{L}+\dot{C v_{c}} \cdot \tilde{v}_{c}
$$

The error dynamic (10), $L \widetilde{i}_{L}$ and $C \widetilde{v}_{c}$ can be represented as:

$$
\left\{\begin{array}{l}
\dot{\tilde{i}}_{L}=-(1-\sigma) \tilde{v}_{c}-R_{\mathrm{i}} \tilde{i}_{L} \\
\tilde{C}_{c}=(1-\sigma) \tilde{i}_{L}-\frac{1}{R} \tilde{v}_{c}
\end{array} .\right.
$$

Then, inserting (13) into (12), we get (14):

$$
\dot{E}_{\mathrm{f}}=-R_{\mathrm{i}} \tilde{i}_{L}^{2}-\frac{1}{R} \tilde{v}_{c}^{2}<0
$$

In practical circuit, $R$ and $R_{\mathrm{i}}>0$. Then, from (14), derivative of $E_{\mathrm{f}}$, is always negative unless $\widetilde{i}_{L}=0$ and $\widetilde{v}_{c}=0$. Hence from (11) and (14), the system is stable.
From [12], the direct control of output voltage does not achieve stability point. Hence an indirect control can be applied to achieve stability point and correspondingly achieve desired objective. Here, the objective of the control design is to charge the $\mathrm{EV}$ battery in $\mathrm{CC}$ and $\mathrm{CV}$ mode along with improved quality of source current with low THD. To achieve nearly unity power factor, the input inductor current should follow the rectified sinusoidal source voltage of same frequency and same phase i.e., $i_{L \mathrm{~d}}=I_{\mathrm{d}}|\sin \omega t| . I_{\mathrm{d}}$ is the desired input inductor current and $I_{\mathrm{d}}=V_{\mathrm{m}} /(1$ $-\sigma)^{2} R . V_{\mathrm{m}}$ is the maximum voltage of input source voltage.

\section{Controller Design}

In PBC strategy, the energy of the system is re-shaped so that a control function can be obtained. The energy re-shaping can be done by injecting virtual damping into the system. A virtual damping factor may be inserted in series with the input inductor or in parallel with the output capacitor. Both methodologies (series and parallel) are discussed here.

\section{1) Series Damping Injection}

In this methodology, a virtual damping factor $R_{\mathrm{i}}$ is inserted in series with the input inductor to modify the energy of the proposed system. Putting $P_{G_{\mathrm{i}}}=0$, in (10), then the obtained closed loop dynamics is:

$$
\left\{\begin{array}{l}
-L \frac{\mathrm{d} \tilde{i}_{L}}{\mathrm{~d} t}=\frac{\partial P}{\partial \tilde{i}_{L}}\left(\tilde{i}_{L}, \tilde{v}_{c}\right)+\frac{\partial P_{R_{i}}}{\partial \tilde{i}_{L}}\left(\tilde{i}_{L}, \tilde{v}_{c}\right) \\
C \frac{\mathrm{d} \tilde{v}_{c}}{\mathrm{~d} t}=\frac{\partial P}{\partial \tilde{v}_{c}}\left(\tilde{i}_{L}, \tilde{v}_{c}\right)
\end{array} .\right.
$$

Subtracting (15) from (7), the closed loop dynamics could be written as:

$$
\left\{\begin{array}{l}
-L \frac{\mathrm{d} i_{L \mathrm{~d}}}{\mathrm{~d} t}=\frac{\partial P}{\partial i_{L \mathrm{~d}}}\left(i_{L \mathrm{~d}}, v_{c \mathrm{~d}}\right)-\frac{\partial P_{R_{\mathrm{i}}}}{\partial \tilde{i}_{L}}\left(\tilde{i}_{L}, \tilde{v}_{c}\right) \\
C \frac{\mathrm{d} v_{c \mathrm{~d}}}{\mathrm{~d} t}=\frac{\partial P}{\partial v_{c \mathrm{~d}}}\left(i_{L \mathrm{~d}}, v_{c \mathrm{~d}}\right)
\end{array} .\right.
$$

From above (16), the closed loop dynamics can be described as:

$$
\left\{\begin{array}{l}
-L \frac{\mathrm{d} i_{L \mathrm{~d}}}{\mathrm{~d} t}=-E+(1-\sigma) v_{c \mathrm{~d}}-R_{\mathrm{i}} \tilde{i}_{L} \\
C \frac{\mathrm{d} v_{c \mathrm{~d}}}{\mathrm{~d} t}=-(1-\sigma) i_{L \mathrm{~d}}-\frac{1}{R} v_{c \mathrm{~d}}
\end{array}\right.
$$

Hence, to control the two objectives of the system, let $i_{L \mathrm{~d}}=I_{\mathrm{d}}$ $|\sin \omega t|$ and $v_{c \mathrm{~d}}=V_{\mathrm{d}}$.

After solving (17), we get control law is as given below: 


$$
\left\{\begin{array}{l}
\sigma=1-\frac{\left(E-L \tilde{i}_{L \mathrm{~d}}+R_{\mathrm{i}} \tilde{i}_{L}\right)}{v_{c \mathrm{~d}}} \\
\dot{v}_{c \mathrm{~d}}=\frac{1}{C}\left[-(1-\sigma) i_{L \mathrm{~d}}-\frac{1}{R} v_{c \mathrm{~d}}\right]
\end{array} .\right.
$$

In this controller, the regulation scheme based on series damping injection. So, the duty ratio is influenced due to series damping factor as the duty ratio depends on the several state variables. From [30], for selection of series damping factor $R_{\mathrm{i}}$ there should be satisfied the following condition:

$$
\left\|\frac{1-\sigma}{R_{\mathrm{i}}} \sqrt{\frac{L}{C}}\right\| \leqslant 1-\delta \Leftrightarrow R_{\mathrm{i}} \geqslant \frac{1-\sigma}{1-\delta} \sqrt{\frac{L}{C}} .
$$

For all $0<\delta<1$.

\section{2)Parallel Damping Injection}

In this methodology, to re-shape the energy of the system, parallel damping factor $G_{\mathrm{i}}$ is inserted in parallel with the output capacitor. Putting $P_{R_{\mathrm{i}}}=0$ in (10), the closed loop dynamics can be rewritten as below:

$$
\left\{\begin{array}{l}
-L \frac{\mathrm{d} \tilde{i}_{L}}{\mathrm{~d} t}=\frac{\partial P}{\partial \tilde{i}_{L}}\left(\tilde{i}_{L}, \tilde{v}_{c}\right) \\
C \frac{\mathrm{d} \tilde{v}_{c}}{\mathrm{~d} t}=\frac{\partial P}{\partial \tilde{v}_{c}}\left(\tilde{i}_{L}, \tilde{v}_{c}\right)+\frac{\partial P_{G_{i}}}{\partial \tilde{v}_{c}}\left(\tilde{i}_{L}, \tilde{v}_{c}\right)
\end{array} .\right.
$$

Subtracting (19) from (7), the closed loop dynamics could be written as:

$$
\left\{\begin{array}{l}
-L \frac{\mathrm{d} i_{L \mathrm{~d}}}{\mathrm{~d} t}=\frac{\partial P}{\partial i_{L \mathrm{~d}}}\left(i_{L \mathrm{~d}}, v_{c \mathrm{~d}}\right) \\
C \frac{\mathrm{d} v_{c \mathrm{~d}}}{\mathrm{~d} t}=\frac{\partial P}{\partial v_{c \mathrm{~d}}}\left(i_{L \mathrm{~d}}, v_{c \mathrm{~d}}\right)-\frac{\partial P_{G_{\mathrm{i}}}}{\partial \tilde{v}}\left(\tilde{i}_{L}, \tilde{v}_{c}\right)
\end{array}\right.
$$

From above (20), the closed loop dynamics can be described as:

$$
\left\{\begin{array}{l}
-L \frac{\mathrm{d} i_{L \mathrm{~d}}}{\mathrm{~d} t}=-E+(1-\sigma) v_{c \mathrm{~d}} \\
C \frac{\mathrm{d} v_{c \mathrm{~d}}}{\mathrm{~d} t}=-(1-\sigma) i_{L \mathrm{~d}}-G v_{c \mathrm{~d}}-G_{\mathrm{i}} \tilde{v}_{c}
\end{array}\right.
$$

Hence, to control the two objectives of the system, let $i_{L \mathrm{~d}}=$ $I_{\mathrm{d}}|\sin \omega t|$ and $v_{\mathrm{cd}}=V_{\mathrm{d}}$ After solving (21), we get control law as given below:

$$
\left\{\begin{array}{l}
\sigma=1-\frac{\left(E-L i_{L \mathrm{~d}}\right)}{v_{c \mathrm{~d}}} \\
\dot{v}_{c \mathrm{~d}}=\frac{1}{C}\left[-(1-\sigma) i_{L \mathrm{~d}}-G v_{c \mathrm{~d}}-G_{\mathrm{i}} \tilde{v}_{c}\right]
\end{array} .\right.
$$

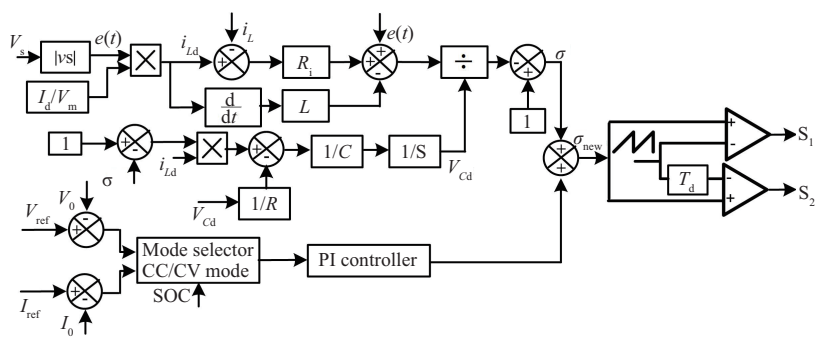

Fig. 4. Schematic block diagram of Brayton-Moser based passivity controller.

In this controller, the regulation scheme depends on parallel damping factor. So, the duty ratio is influenced due to parallel damping factor. From [30], for selection of parallel damping factor $G_{\mathrm{i}}$ there should be satisfied the following condition:

$$
\left\|\frac{1-\sigma}{G_{\mathrm{i}}} \sqrt{\frac{C}{L}}\right\| \leqslant 1-\delta \Leftrightarrow G_{\mathrm{i}} \geqslant \frac{1-\sigma}{1-\delta} \sqrt{\frac{C}{L}}-G
$$

For all $0<\delta<1$.

In order to obtain desired objective, the controller is designed in which damping factor is injected in series with the input inductor and in parallel with the capacitor. But here, the series damping injected controller is implemented only because a load is already connected in parallel to the capacitor and parallel damping injected controller is not appropriate for PFC.

To improve the dynamic performances of the aforesaid controller, a PI controller is integrated with the conjunction to the aforesaid controller. Due to the addition of the PI controller, the steady-state errors easily eliminated, and the system quickly stabilizes. So, after adding a PI controller in parallel to the aforesaid controller a new control law is obtained, i.e.,

$$
\sigma_{\text {new }}=\sigma+k_{\mathrm{P}} e(t)+k_{\mathrm{i}} \int e(t) \mathrm{d} t,
$$

where $k_{\mathrm{p}}, k_{\mathrm{i}}$ are the gain of the PI controller and $e(t)=V_{\text {ref }}-$ $V_{0}$, the output voltage error in CV mode and $e(t)=I_{\text {ref }}-I_{0}$, the output current error in $\mathrm{CC}$ mode.

\section{Results AND Discussions}

A Simulink model of the proposed BM-PBC controller for the TL boost PFC converter, rated for $2.8 \mathrm{~kW}$ is developed using the Simulink and the Sim Power System toolbox of MATLAB. The specifications of system parameter include AC input supply voltage $\left(v_{\mathrm{s}}\right): 230 \mathrm{~V}, 50 \mathrm{~Hz}$ inductor $(L): 6$ $\mathrm{mH}$, capacitors $\left(C_{1}, C_{2}\right): 2500 \mu \mathrm{F}$ with switching frequency of $5 \mathrm{kHz}$. The proposed controller is used to charge a lithiumion battery of rated capacity $35 \mathrm{Ah}$, with nominal voltage of $345 \mathrm{~V}$ under $\mathrm{CC}$ and $\mathrm{CV}$ modes. In CC mode, battery starts charging with state of charge (SOC) of $30 \%$ at $7 \mathrm{~A}$ current load i.e., $\mathrm{C} / 5$ rate and in $\mathrm{CV}$ mode, battery is charged with $70 \%$ $\mathrm{SOC}$ at $\mathrm{CV}$ of $400 \mathrm{~V}$. The BM PBC control methodology is same for both modes of battery charging, but in $\mathrm{CV}$ mode, the output DC voltage of converter is sensed and compare with constant reference voltage of $400 \mathrm{~V}$ and in $\mathrm{CC}$ mode, the load current is sensed and compare with constant reference current of $7 \mathrm{~A}$ as shown in Fig. 4. Depending upon the SOC of the 


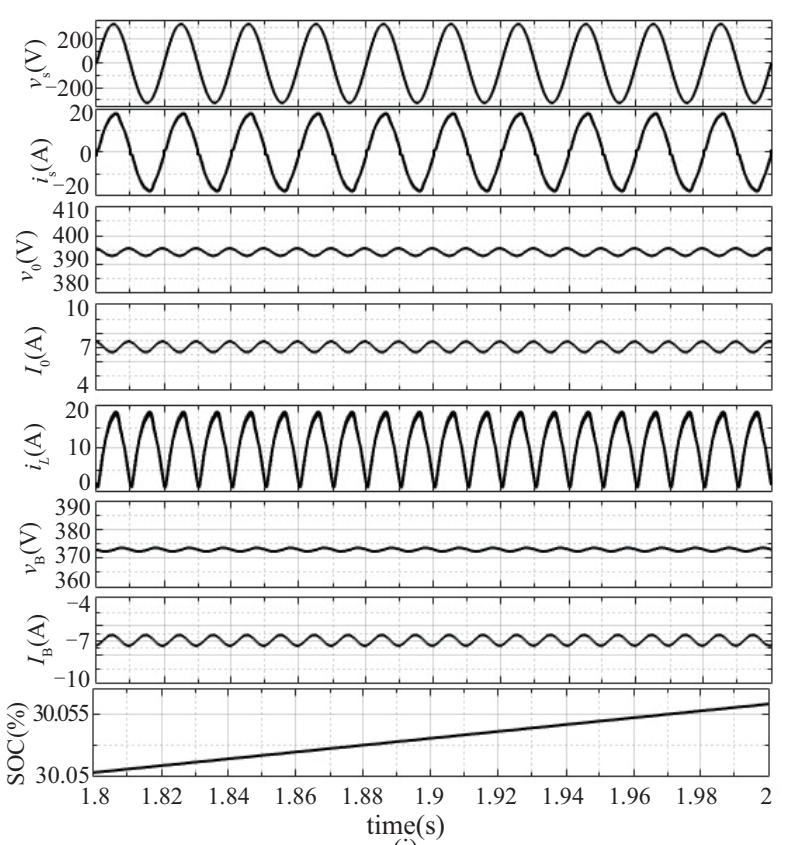

(i)
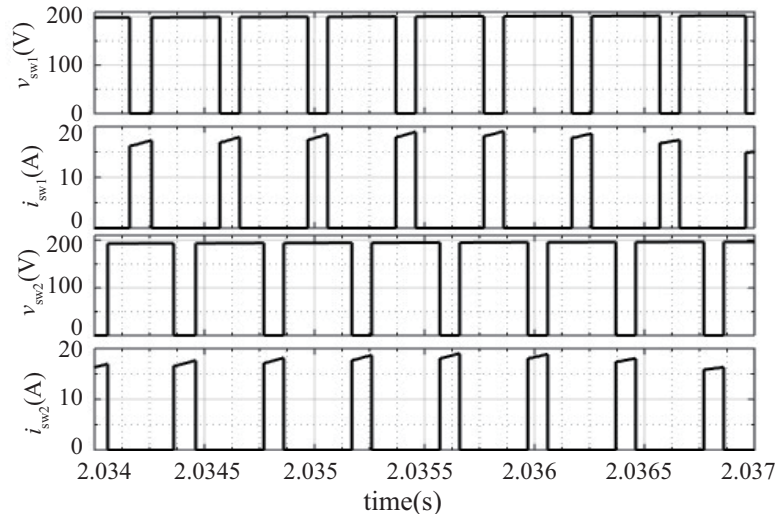

(ii)

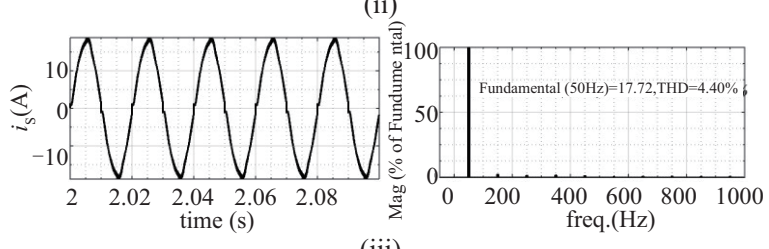

(iii)

(a)
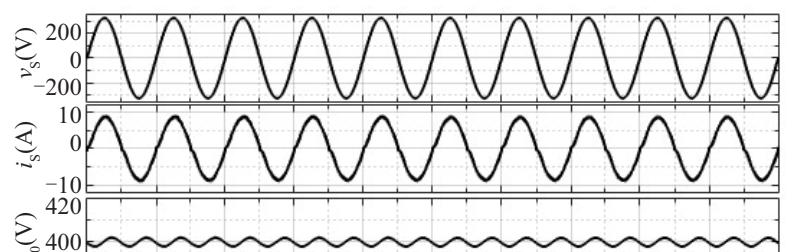

380
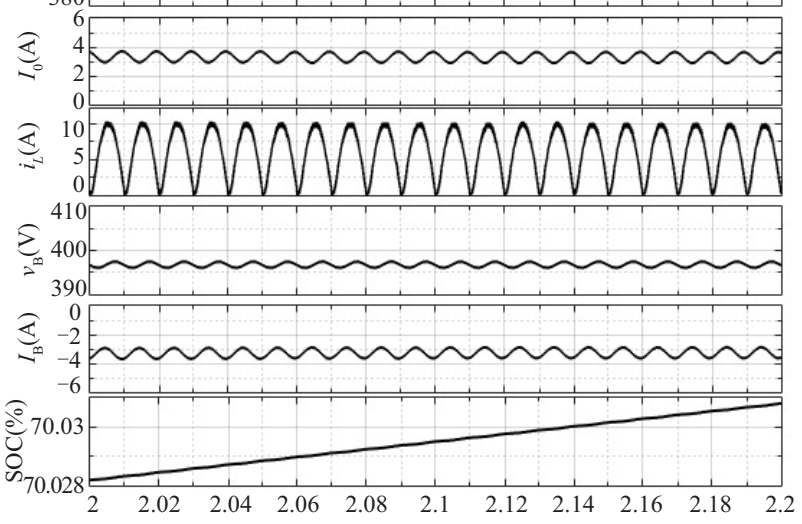

time(s)
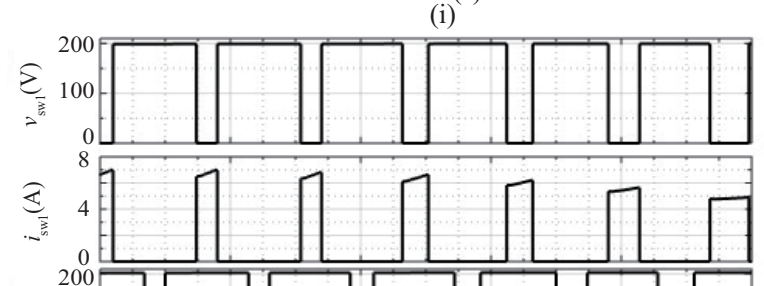

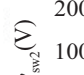
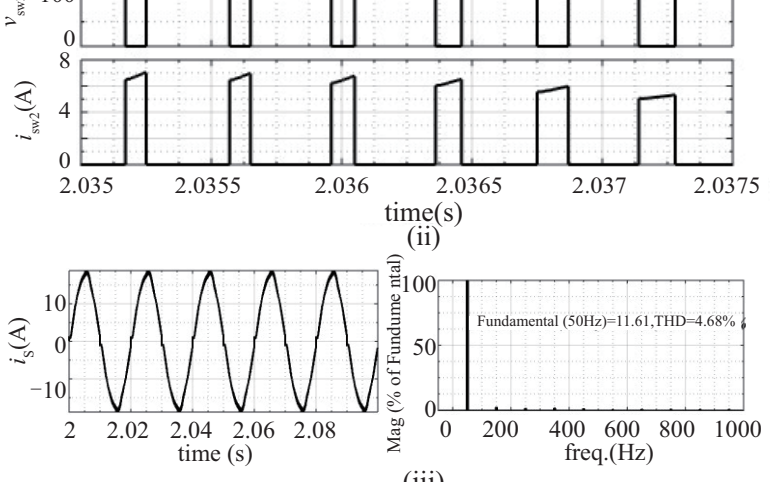

(iii)

(b)

Fig. 5. The steady state waveforms feeding battery load with the BM-PBC (i) $v_{\mathrm{s}}, i_{\mathrm{s}}, V_{0}, I_{0}, i_{\mathrm{L}}, V_{\mathrm{B}}, I_{\mathrm{B}}$, SOC, (ii) $v_{\mathrm{swl}}, i_{\mathrm{swl}}, v_{\mathrm{sw} 2}, i_{\mathrm{sw} 2}$, (iii) harmonic spectrum of supply current of converter, under (a) CC mode and (b) CV mode.

battery, aforesaid modes are selected by mode selector block. The steady state and dynamic performances of the aforesaid controller are investigated for battery load under both CC and CV mode and obtained results are discussed in Figs. 5 and 6.

\section{A. Simulation Study of the TL Boost Converter}

\section{1)Steady State Performance}

The simulation study of the BM-PBC based controller for the TL boost PFC converter employed for charging battery (35 Ah) under CC mode or in CV mode is carried out with MATLAB software. As conventional practice, the battery is charged in CC mode with $30 \%$ of SOC and after some time when SOC reached to, $70 \%-80 \%$, the converter operation is shifted to $\mathrm{CV}$ mode. Fig. 5 depicts steady state response for the BM-PBC of the TL boost PFC converter feeding battery load under $\mathrm{CC}$ and $\mathrm{CV}$ mode at source voltage $\left(v_{\mathrm{s}}\right): 230 \mathrm{~V}, 50$ Hz Fig. 5(a)(i) and (b)(i) depicts waveforms of source voltage $\left(v_{\mathrm{s}}\right)$, source current $\left(i_{\mathrm{s}}\right)$, output voltage $\left(V_{\mathrm{o}}\right)$, load current $\left(I_{\mathrm{o}}\right)$, input inductor current $\left(i_{L}\right)$, battery voltage $\left(V_{\mathrm{B}}\right)$, battery current $\left(I_{\mathrm{B}}\right)$ and SOC for $\mathrm{CC}$ and $\mathrm{CV}$ mode respectively. It has been observed that in $\mathrm{CC}$ mode, the battery has been charged with $\mathrm{CC}$ of $7 \mathrm{~A}$ and in $\mathrm{CV}$ mode, $\mathrm{CV}$ of $400 \mathrm{~V}$ with maintained input PF closed to unity in both modes. Fig. 5(a)(ii) and (b) 


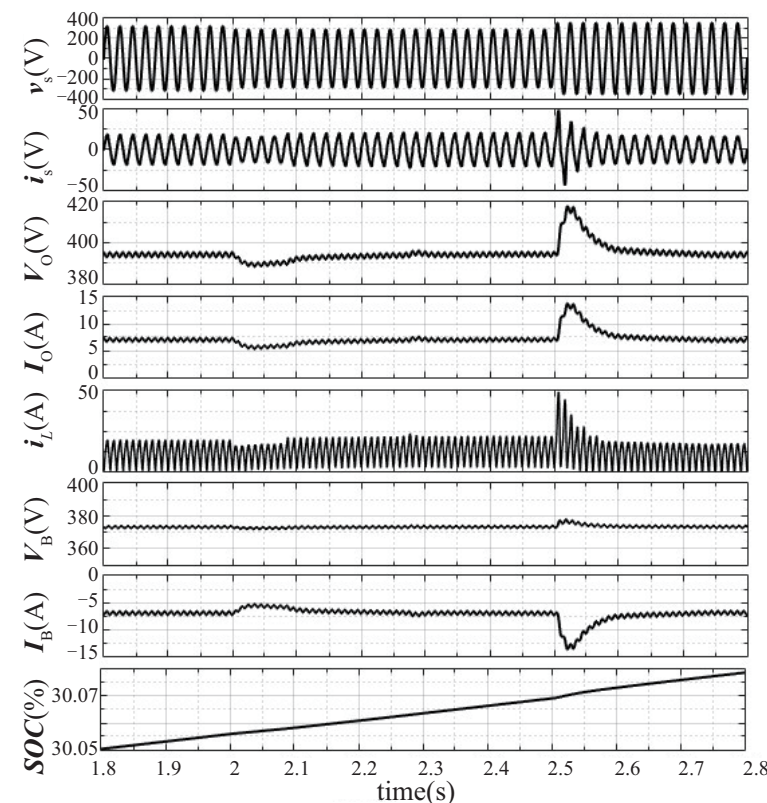

(a)

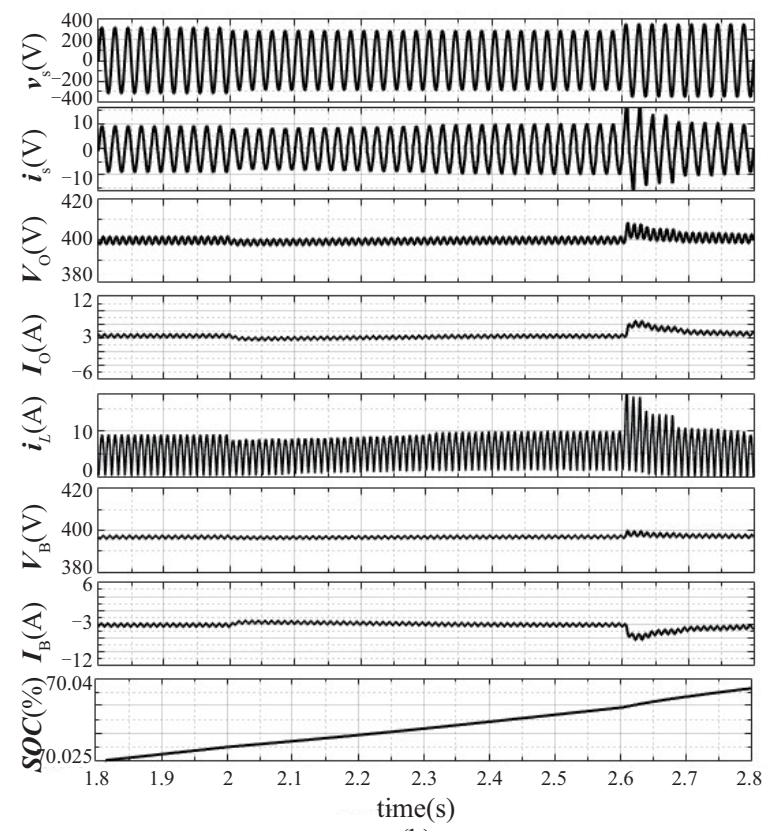

(b)

Fig. 6. Dynamic response of converter feeding battery load under step decrease in supply voltage by $10 \%$ at time $t=2 \mathrm{~s}$ and increase $10 \%$ from nominal value $(230 \mathrm{~V})$ at time instant $t=2.5 \mathrm{~s}$ under (a) CC mode and (b) $\mathrm{CV}$ mode.

also depicts waveforms of voltage across switches $\left(v_{\mathrm{SW} 1}\right.$, $\left.v_{\mathrm{SW} 2}\right)$ and switch currents $\left(i_{\mathrm{SW} 1}, i_{\mathrm{SW} 2}\right)$ for $\mathrm{CC}$ and $\mathrm{CV}$ mode respectively. The fast Fourier transfor (FFT) analysis is also done and depicted in Figs. 5(a)(iii) and (b) which indicates, at steady state total harmonics distortion is $3.17 \%$ and $4.55 \%$ for $\mathrm{CC}$ and $\mathrm{CV}$ mode respectively which is below $5 \%$, according to IEEE standard.

\section{2)Dynamic Response Under Input Variations}

Fig. 6(a-b) depict dynamic performance against source variation of the TL boost converter in $\mathrm{CC}$ and $\mathrm{CV}$ charging

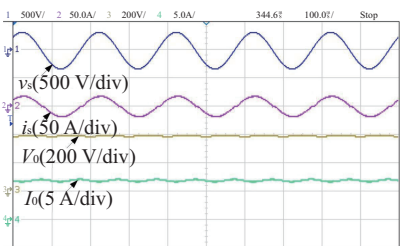

(i)

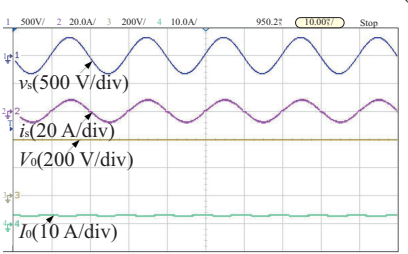

(i)

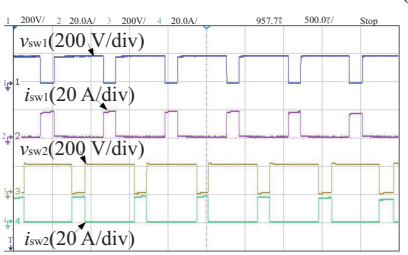

(i)

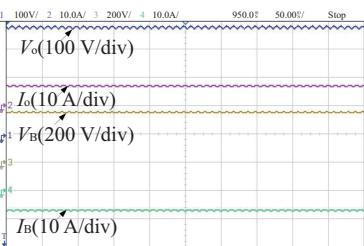

(ii)

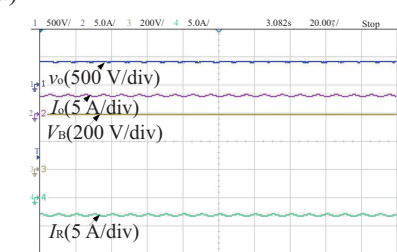

(ii)

(b)

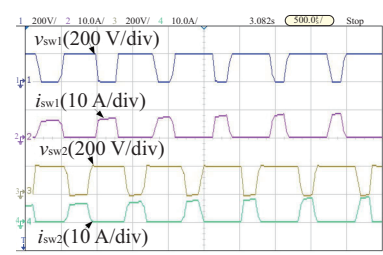

(ii) (c)

Fig. 7. Steady state performance of converter with battery load under (a) CC mode: (i) $v_{\mathrm{s}}, i_{\mathrm{s}}, V_{0} I_{0}$ and (ii) $V_{0}, I_{0}, V_{\mathrm{B}}$ and $I_{\mathrm{B}}$ (b) $\mathrm{CV}$ mode: (i) $v_{\mathrm{s}}, i_{\mathrm{s}}, V_{0}, I_{0}$ and (ii) $V_{0}, I_{0} V_{\mathrm{B}}, I_{\mathrm{B}}$. (c) Voltage and current of switches $\mathrm{S}_{1}, \mathrm{~S}_{2}: v_{\mathrm{sw} 1}, i_{\mathrm{sw1}}, v_{\mathrm{sw} 2}$, $i_{\mathrm{sw2}}$ : (i) CC mode and (ii) CV mode.

mode. First, the supply voltage decreased by $10 \%$ then increased by $10 \%$ from its nominal value $(230 \mathrm{~V})$ at $t=2 \mathrm{~s}$ and $t=2.5 \mathrm{~s}$ respectively. As observed from the simulation study, the battery has been charged with CC (7A) in CC mode and with $\mathrm{CV}(400 \mathrm{~V})$ in $\mathrm{CV}$ mode against source variation. The input source current is purely sinusoidal and in phase with source voltage which demonstrates the unity power factor as presented in Fig. 6. Fig. 6 also show SOC of the battery gradually increases in both $\mathrm{CC}$ and $\mathrm{CV}$ modes.

\section{B. Test Results of the TL Boost Converter}

The real-time validation of the proposed controller is implemented with TL boost converter with the similar parameters as used in the simulation study and its performances are observed under battery load. The real-time simulator OP5142 which is FPGA based XC3S5000 series processor, is used to implement Brayton-Moser based PBC controller. A 4-channel Digital Storage Oscilloscope-DSO-X-2004A and a Fluke power quality analyzer (43B) are used for measuring and recording the test results. The several test results are obtained while charging the EV battery under $\mathrm{CC}$ and $\mathrm{CV}$ mode and few of them are presented in Figs. 7-9. To monitor the power quality features of supply current under different charging modes, are harmonic spectra of source current is recorded using Fluke power quality analyzer (43B) and its results are presented.

\section{1)Steady State Response}

The test performance under steady state of the TL boost 


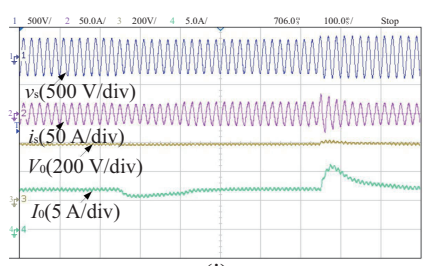

(i)

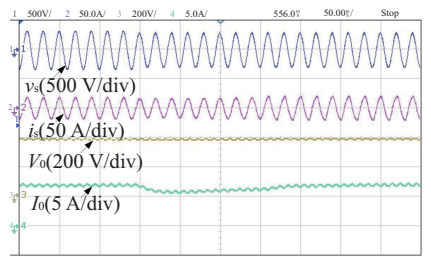

(iii)

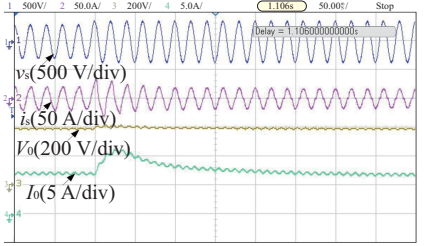

(v)

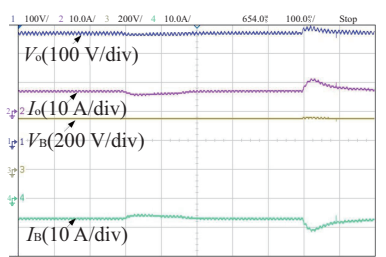

(ii)

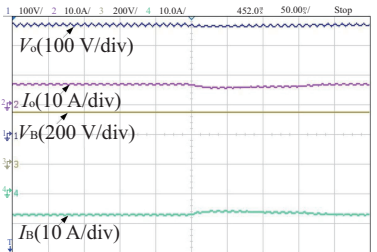

(iv)

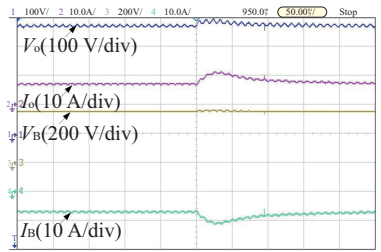

(vi)

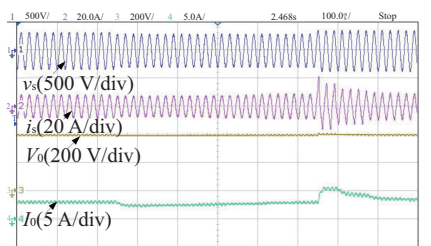

(i)

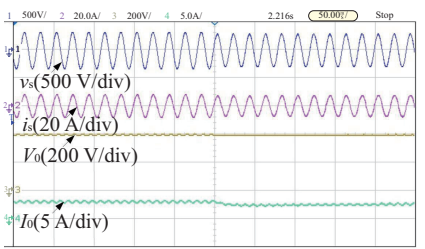

(iii)

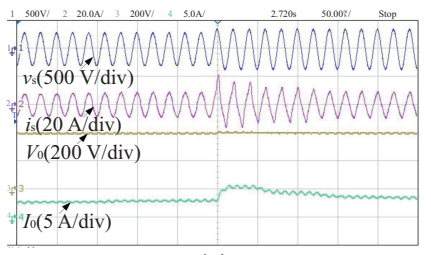

(v)

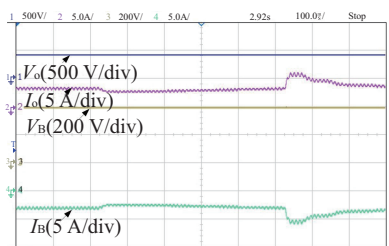

(ii)

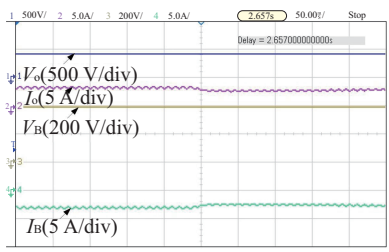

(iv)

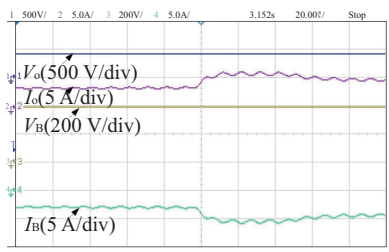

(vi)

(a)

(b)

Fig. 8. Dynamic performance of the converter with battery load under (a) CC mode and (b) CV mode. (i) Waveforms of $v_{\mathrm{s}}, i_{\mathrm{s}}, V_{0}$ and $I_{0}$ against supply voltage variations. (ii) Waveforms of $V_{0}, I_{0}, V_{\mathrm{B}}$ and $I_{\mathrm{B}}$ against supply voltage variations. (iii) Waveforms of $v_{\mathrm{s}}, i_{\mathrm{s}}, V_{0}$ and $I_{0}$ during supply voltage decrease $10 \%$. (iv) Waveforms of $V_{0}, I_{0}, V_{\mathrm{B}}$ and $I_{\mathrm{B}}$ during supply voltage decrease $10 \%$. (v) Waveforms of $v_{\mathrm{s}}, i_{\mathrm{s}}, V_{0}$ and $I_{0}$ during supply voltage increase $10 \%$. (vi) Waveforms of $V_{0}, I_{0}, V_{\mathrm{B}}$ and $I_{\mathrm{B}}$ during supply voltage increase $10 \%$.

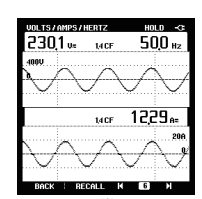

(i)

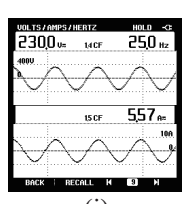

(i)

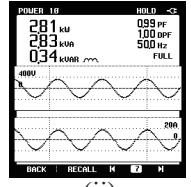

(ii)

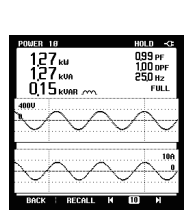

(ii)

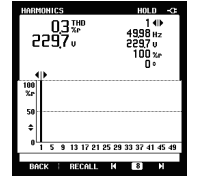

(iii)

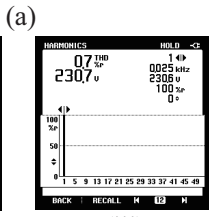

(iii)

(b)

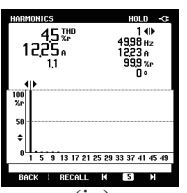

(iv)

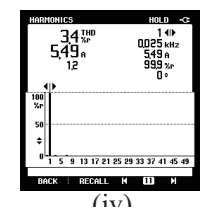

(iv)

Fig. 9. Power quality assessment of input supply voltage and source current of the system with battery load under (a) CC mode and (b) $\mathrm{CV}$ mode. (i) $v_{\mathrm{s}}$ and $i_{\mathrm{s}}$, (ii) $P_{\mathrm{s}}$ and $Q_{\mathrm{s}}$, (iii) harmonic spectrum of $i_{\mathrm{s}}$ and (iv) harmonic spectrum of $v_{\mathrm{s}}$.

PFC for the BM-PBC in CC and CV charging mode at supply voltage $\left(v_{\mathrm{s}}\right): 230 \mathrm{~V}, 50 \mathrm{~Hz}$ is presented in Fig. 7(a) and (b). Fig. 7(a) shows the battery is charging with $\mathrm{CC}(7 \mathrm{~A})$ in $\mathrm{CC}$ mode along with purely sinusoidal input source current and in same phase with the input supply voltage. Similarly, EV battery is charging with $\mathrm{CV}$ of $(400 \mathrm{~V})$ in $\mathrm{CV}$ mode along with nearly unity power factor as presented in Fig. 7(b). Fig. 7(c)(i-ii) show the switch voltages $\left(v_{\mathrm{SW} 1}, v_{\mathrm{SW} 2}\right)$ and switch currents $\left(i_{\mathrm{SW} 1}\right.$, $i_{\mathrm{SW} 2}$ ) for both switches, for both modes (CC and CV).

\section{2)Test Results Under Battery Load for Dynamic Response}

The dynamic performance of the TL boost converter with $\mathrm{BM}-\mathrm{PBC}$ in $\mathrm{CC}$ and $\mathrm{CV}$ charging mode is depicted in Fig. 8.

The dynamic performance against input source variation from $230 \mathrm{~V}$ to $207 \mathrm{~V}$ are displayed in Fig. 8(a)(iii) and (b)(iii) for CC and CV mode respectively and input source variation from 207 $\mathrm{V}$ to $253 \mathrm{~V}$ is shown in Fig. 8(a)(v) and (b)(v) for CC and CV mode respectively. The waveforms of the battery parameters $\left(V_{\mathrm{B}}, I_{\mathrm{B}}\right)$ are also recorded against input variation and observed satisfactory results.

Fig. 9 shows the results of Fluke power analyzer which provides waveforms and THD of source voltage $\left(v_{\mathrm{s}}\right)$ and source current $\left(i_{\mathrm{s}}\right)$ with their harmonic spectrums for $\mathrm{CC}$ and $\mathrm{CV}$ modes battery charger at source voltage $\left(v_{\mathrm{s}}\right): 230 \mathrm{~V}, 50 \mathrm{~Hz}$ Fig. 9(a)(iii) and (iv) shows the THD of $0.3 \%$ and $4.5 \%$ in source voltage and source current respectively, under CC mode battery charger. In $\mathrm{CV}$ mode, when the proposed converter rated at $1.27 \mathrm{~kW}$ is supplied at nominal voltage $(230 \mathrm{~V})$, the observed THD in source voltage is $0.7 \%$ and in source current is 3.4\% as displayed in Fig. 9(b)(iii) and (iv). As observed from recorded data, the THD for both loads are less than 5\%, which validate the range of the IEEE standard.

The comparative performance of the proposed controller against benchmark conventional PI controller under resistive load is depicted in Fig. 10. The efficiency curve under the variation of input voltage and output power is presented in Fig. 10 (a) and (b) and it is observed that the efficiency of the both controllers are lies in $96 \%-97 \%$. The THD curve of the input current against input voltage and output power is also observed and presented in Fig. 10(c)-(d). The THD of the input current of the proposed controller is less than $10 \%$ against dynamics conditions. The comparative study of the proposed controller 


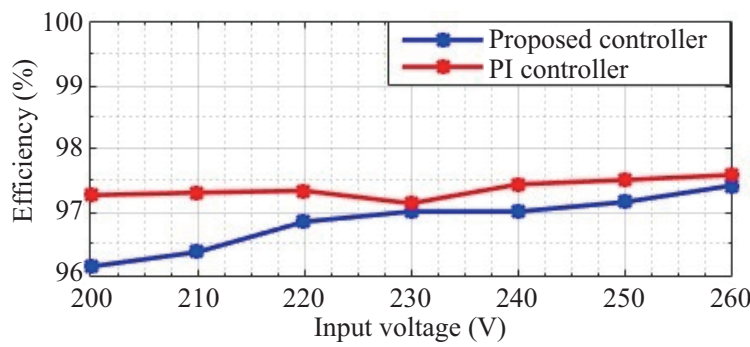

(a)

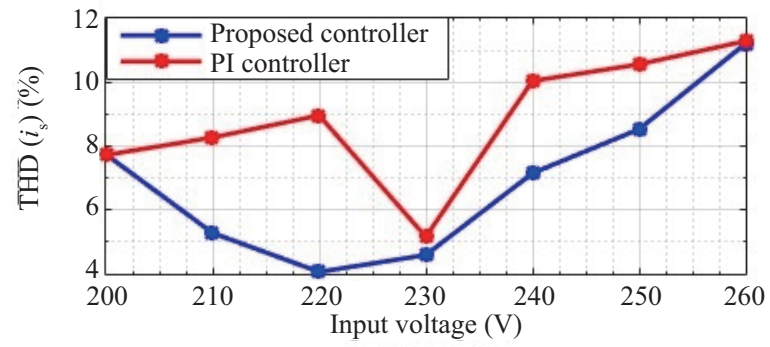

(c)

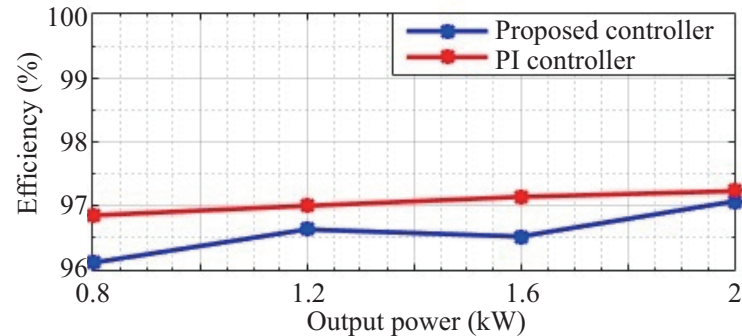

(b)

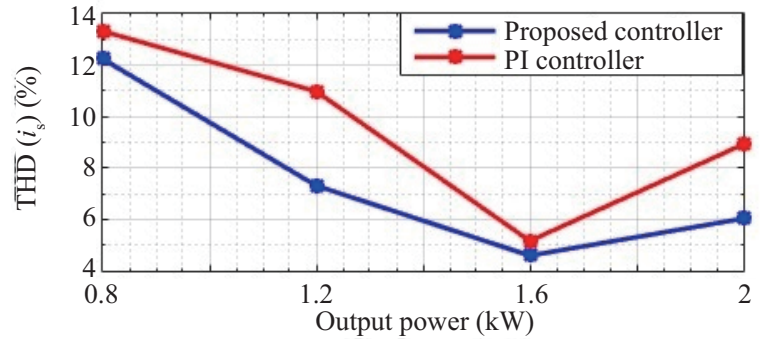

(d)

Fig. 10. Comparative performance curve: (a) efficiency vs. input voltage, (b) efficiency vs. output power, (c) source current THD vs. input voltage and (d) source current THD vs. output power.

TABLE I

Comparative Study Against Input Voltage Variation

\begin{tabular}{|c|c|c|c|c|c|c|c|c|}
\hline \multirow{2}{*}{ Input voltage $/ \mathrm{V}$} & \multicolumn{4}{|c|}{ Proposed controller } & \multicolumn{4}{|c|}{ PI controller } \\
\hline & Peak overshoot $/ \%$ & Rise time/s & Peak time/s & Settling time/s & Peak overshoot $/ \%$ & Rise time/s & Peak time/s & Settling time/s \\
\hline 207 & 31.50 & 0.022 & 0.032 & 0.36 & 31.75 & 0.028 & 0.036 & 0.38 \\
\hline 230 & 42.50 & 0.019 & 0.031 & 0.39 & 43.75 & 0.024 & 0.038 & 0.41 \\
\hline 254 & 49.00 & 0.018 & 0.029 & 0.38 & 49.25 & 0.024 & 0.036 & 0.41 \\
\hline
\end{tabular}

TABLE II

Comparative Study Against Output Power Variation

\begin{tabular}{|c|c|c|c|c|c|c|c|c|}
\hline \multirow{2}{*}{ Output power $/ \mathrm{kW}$} & \multicolumn{4}{|c|}{ Proposed controller } & \multicolumn{4}{|c|}{ PI controller } \\
\hline & Peak overshoot/\% & Rise time/s & Peak time/s & Settling time $/ \mathrm{s}$ & Peak overshoot $/ \%$ & Rise time/s & Peak time $/ \mathrm{s}$ & Settling time $/ \mathrm{s}$ \\
\hline 1.6 & 42.50 & 0.019 & 0.031 & 0.39 & 43.75 & 0.024 & 0.038 & 0.41 \\
\hline 2.0 & 41.25 & 0.020 & 0.031 & 0.37 & 42.35 & 0.026 & 0.037 & 0.39 \\
\hline 2.4 & 40.25 & 0.020 & 0.031 & 0.38 & 41.50 & 0.026 & 0.037 & 0.39 \\
\hline
\end{tabular}

against benchmark conventional PI controller is also done in terms of control parameters like peak overshoot, rise time, peak time and settling time against input source and output power variations as presented in Tables I and II respectively. It is observed that the proposed controller BM-PBC achieve stability point faster than conventional PI controller. The performance curve of the aforesaid system with proposed controller is presented in Fig. 11 for both charging mode (CC and CV). Fig. 11(a) and (b) shows the efficiency curve against input voltage variation for $\mathrm{CC}$ and $\mathrm{CV}$ mode respectively. It is observed that efficiency is varying around $96 \%-97 \%$ against large variation of input voltage in $\mathrm{CC}$ mode and for $\mathrm{CV}$ mode, it is $94 \%-96 \%$. The plot of THD against input variation is shown in Fig. 11(c) and (d) for both CC and CV mode. It is observed that the THD is less than $10 \%$ for both modes (CC and $\mathrm{CV}$ ) against input variation.

\section{CONCLUSION}

In this paper, the mathematical model of the TL boost PFC converter is developed using the Brayton-Moser formulation and then BM-PBC based controller is established. The proposed controller is based on energy modification in which its control of energy is done through suitable damping injection by incorporating a virtual resistor in series with the inductor or in parallel to the capacitor. The stability analysis is also carried out with the help of Lyapunov stability. To improve the dynamic performance and to reduce the steady state 


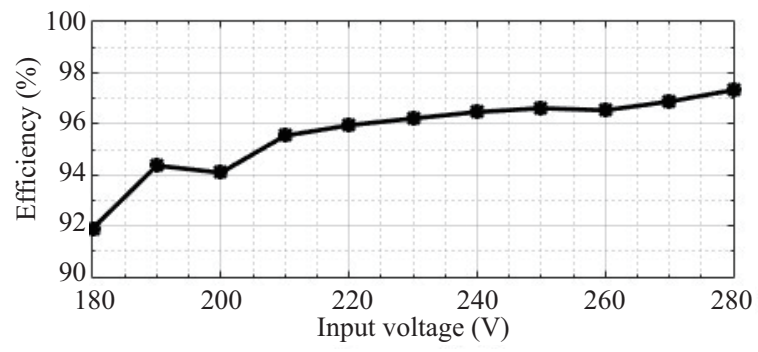

(a)

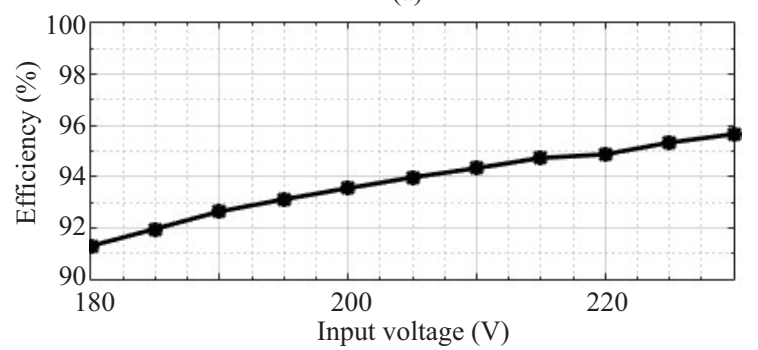

(b)

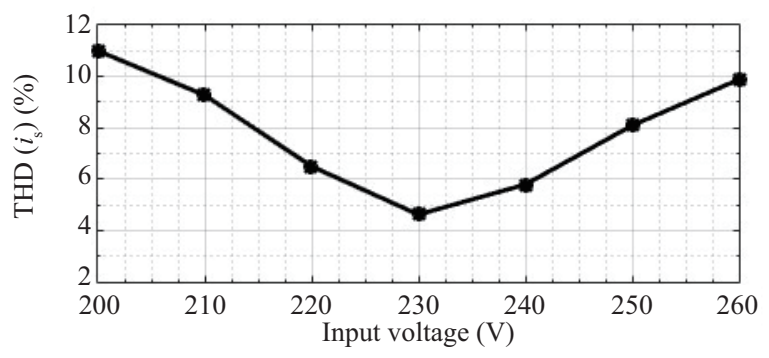

(c)

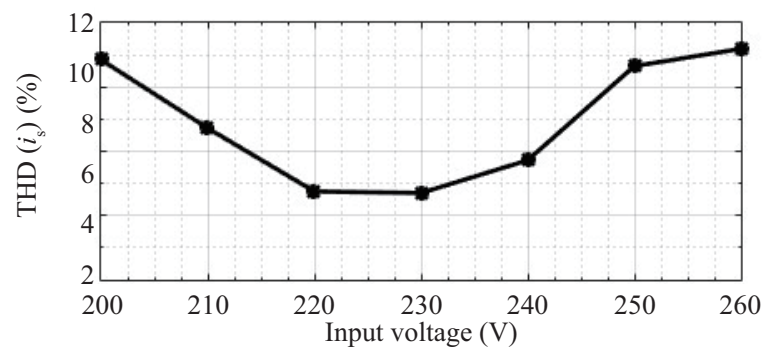

(d)

Fig. 11. Performance curve: efficiency vs. input source voltage under (a) CC mode and (b) CV mode. The source current THD vs. input source voltage under and (c) CC mode and (d) CV mode.

errors, a PI controller is integrated in conjunction with the proposed controller. The Brayton-Moser based PBC controller for TL boost converter is simulated using Matlab software and validated through hardware in loop (HIL) using FPGA based XC3S5000 series processor of real-time simulator OP-5142. The proposed system is employed as an on-board battery charger to charge the EV battery under $\mathrm{CC}$ and $\mathrm{CV}$ modes. It has satisfactory output response under steady-state and dynamic response and it is observed that the aforesaid passivity-based controller control strategies for the TL boost exhibits good power qualities under different operating conditions. The total harmonic distortion of input source current is also observed for both charging mode (CC and CV) and it is found below $5 \%$ which fulfilled the criteria of IEEE standard and IEC 61000-3-2. It is also observed that design of passivity-based control is simple and robust against dynamic variations.

\section{REFERENCES}

[1] S. S. Williamson, Energy Management Dtrategies for Electric and PlugIn Hybrid Electric Vehicles. NewYork, NY, USA: Springer, 2013.

[2] J. Larminie and J. Lowry, Electric Vehicle Technology Explained. Swindon, UK.: John Wiley \& Sons, 2012.

[3] IEEE Recommended Practices and Requirements for Harmonic Control in Electrical Power Systems, IEEE standard, 519-1992.

[4] J. Linares-Flores, H. Sira-Ramirez, J. Reger, and S. Hernandez-Marcial, "A boost unity power factor pre-compensator," in 2008 IEEE Power Electronics Specialists Conference, Rhodes, Greece, 2008, pp. 36233627.

[5] R. W. Erickson and D. Maksimovic, Fundamentals of Power Electronics $\left(2^{\text {nd }}\right.$ ed). New York, NY, USA: Springer,2007.

[6] X. Ruan, B. Li, Q. Chen, S.-C. Tan, and K. T. Chi,"Fundamental considerations of three-level DC-DC converters: Topologies, analyses, and control," in IEEE Transactions on Circuits and Systems I: Regular Papers, vol. 55, no. 11, pp. 3733-3743, Dec. 2008.

[7] W.-Y. Choi and S.-J. Lee,"Three-level SEPIC with improved efficiency and balanced capacitor voltages," in Journal of Power Electronics, vol. 16, pp. 447-454, 2016.

[8] R. D. Middlebrook and S. Cuk,"A general unified approach to modelling switching-converter power stages," in 1976 IEEE Power Electronics Specialists Conference, Cleveland, OH, USA, 1976, pp. 18-34.

[9] D. Jeltsema, "Modeling and control of nonlinear networks: a power-based perspective," Netherlands, UK, 2005.

[10] H. A. Yildiz and L. Goren-Sumer, "Lagrangian modeling of DC-DC buck-boost and flyback converters," in 2009 European Conference on Circuit Theory and Design, Antalya, Turkey, 2009, pp. 245-248.

[11] J. M. Scherpen, D. Jeltsema, and J. B. Klaassens, "Lagrangian modeling of switching electrical networks," in Systems \& Control Letters, vol. 48, no. 5, pp. 365-374, Apr. 2003.

[12] R. Ortega, J. A. L. Perez, P. J. Nicklasson, and H. J. Sira-Ramirez, Passivity-Based Control of Euler-Lagrange Systems: Mechanical, Electrical and Electromechanical Applications ( $1^{\text {st }}$ edition ). UK.:SpringerVerlag London, 1998.

[13] G. Escobar, A. J. van der Schaft, and R. Ortega, "A Hamiltonian viewpoint in the modeling of switching power converters," in Automatica, vol. 35, no. 3, pp. 445-452, Mar. 1999.

[14] H. Sira-Ramirez, "Nonlinear P-I controller design for switchmode DCto-DC power converters," in IEEE Transactions on Circuits and Systems, vol. 38, no. 4, pp. 410-417, Apr. 1991.

[15] B. J. Patella, A. Prodic, A. Zirger, and D. Maksimovic, "High-frequency digital PWM controller IC for DC-DC converters," in IEEE Transactions on Power Electronics, vol. 18, no. 1, pp. 438-446, Jan. 2003.

[16] P. Mattavelli, L. Rossetto, G. Spiazzi, and P. Tenti, "General-purpose fuzzy controller for DC-DC converters," in IEEE Transactions on Power Electronics, vol. 12, no. 1, pp. 79-86, Jan. 1997.

[17] W. Stefanutti, P. Mattavelli, S. Saggini, and M. Ghioni, "Autotuning of digitally controlled DC-DC converters based on relay feedback," in IEEE Transactions on Power Electronics, vol. 22, no. 1, pp. 199-207, Jan. 2007.

[18] S. Baev, Y. Shtessel, H. Biglari, and R. Adhami, "Sliding mode control of a unity power factor AC-to-DC boost converter," in 2007 46th IEEE Conference on Decision and Control, New Orleans, LA, USA, 2007, pp. 2005-2010.

[19] H. S. H. Chung, E. P. W. Tam, and S. Y. R. Hui, "Development of a fuzzy logic controller for boost rectifier with active power factor correction," in 30th Annual IEEE Power Electronics Specialists Conference Record (Cat. No.99CH36321), Charleston, SC, USA, 1999, pp. 149-154 vol.1.

[20] M. Saleh, Y. Esa, Y. Mhandi, W. Brandauer, and A. Mohamed, "Design and implementation of CCNY DC microgrid testbed," in 2016 IEEE Industry Applications Society Annual Meeting, Portland, OR, USA, 2016, 
pp. $1-7$.

[21] T. F. Wu, C. H. Chang, and Y. H. Chen, "A fuzzy-logic-controlled singlestage converter for PV-powered lighting system applications," in IEEE Transactions on Industrial Electronics, vol. 47, no. 2, pp. 287-296, Apr. 2000.

[22] M. Abedi, B. Song, and R. Kim, "Nonlinear-model predictive control based bidirectional converter for $\mathrm{V} 2 \mathrm{G}$ battery charger applications," in 2011 IEEE Vehicle Power and Propulsion Conference, Chicago, IL, USA, 2011, pp. 1-6.

[23] R. Ortega and M. W. Spong, "Adaptive motion control of rigid robots: a tutorial," in Proceedings of the 27th IEEE Conference on Decision and Control, Austin, TX, USA, 1988, pp. 1575-1584, vol.2.

[24] R. Ortega, A. van der Schaft, B. Maschke, and G. Escobar, "Interconnection and damping assignment passivity-based control of port-controlled Hamiltonian systems," in Automatica, vol. 38, no. 4, pp. 585-596, Apr. 2002.

[25] H. Sira-Ramirez and M. D. deNieto, "A Lagrangian approach to average modeling of pulsewidth-modulation controlled DC-to-DC power converters," in IEEE Transactions on Circuits and Systems I: Fundamental Theory and Applications, vol. 43, no. 5, pp. 427, May 1996.

[26] H. Sira-Ramirez, R. Ortega, and G. Escobar, "Lagrangian modeling of switch regulated DC-to-DC power converters," in Proceedings of 35th IEEE Conference on Decision and Control, Kobe, Japan, 1996, pp. 4492-4497, vol.4.

[27] J. M. Scherpen, D. Jeltsema, and J. B. Klaassens, "Lagrangian modeling and control of switching networks with integrated coupled magnetics," in Proceedings of the 39th IEEE Conference on Decision and Control (Cat. No. 00CH37187), Sydney, NSW, Australia, 2000, pp. 4054-4059, vol.4.

[28] O. D. M. Giraldo, A. G. Ruiz, I. O. Velázquez, and G. R. E. Pérez, "Passivity-based control for battery charging/discharging applications by using a buck-boost DC-DC converter," in IEEE Green Technologies Conference (GreenTech), Austin, TX, 2018, pp. 89-94.

[29] M. R. Mojallizadeh and M. A. Badamchizadeh, "Adaptive passivitybased control of a photovoltaic/battery hybrid power source via algebraic parameter identification," in IEEE Journal of Photovoltaics, vol. 6, no. 2, pp. 532-539, Mar. 2016.

[30] D. Jeltsema and J. M. A. Scherpen, "Tuning of passivity-preserving controllers for switched-mode power converters," in IEEE Transactions on Automatic Control, vol. 49, no. 8, pp. 1333-1344, Aug. 2004.

[31] M. M. J. de Vries, M. J. Kransse, M. Liserre, V. G. Monopoli, and J. M. A. Scherpen, "Passivity-based harmonic control through series/parallel damping of an H-bridge rectifier," in 2007 IEEE International Symposium on Industrial Electronics, Vigo, Spain, 2007, pp. 3385-3390.

[32] H. Zhou, A. M. Khambadkone, and X. Kong, "Passivity-based control for an interleaved current-fed full-bridge converter with a wide operating range using the Brayton-Moser form," in IEEE Transactions on Power Electronics, vol. 24, no. 9, pp. 2047-2056, Sep. 2009.

[33] R. K. Brayton and J. K. Moser, "A theory of nonlinear networks. I," in Quarterly of Applied Mathematics, vol. 22, no. 1, pp. 1-33, Apr. 1964.

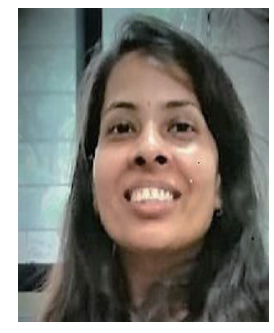

Kumari Shipra received her B.S. degree in engineering in electrical engineering from the Muzaffurpur Institute of Technology, Muzaffurpur, India, in 2003, and M.E. degree in electrical engineering with a specialization in control and instrumentation from the Delhi College of Engineering (now Delhi Technological University), Delhi, India in 2012. She is currently working toward her Ph.D. degree in electrical engineering at the Sardar Vallabhbhai National Institute of Technology, Surat, India. From 2008 to 2014, she was working in Inderprastha Engineering College, Ghaziabad, India as an Assistant Professor. Her current research interests include the passivity-based controllers, high power factor AC/DC converter and battery charger.

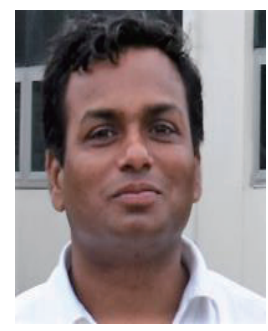

Rakesh Maurya received his B.Tech. degree in electrical engineering from the Kamla Nehru Institute of Technology, Sultanpur, India, in 1998, M.T. degree in power electronics and electric drive and $\mathrm{Ph} . \mathrm{D}$. degree in electrical engineering from the Indian Institute of Technology Roorkee, Roorkee, India, in 2002 and 2014 respectively. He is currently serving as an Associate Professor in the Department of Electrical Engineering, Sardar Vallabhbhai National Institute of Technology, Surat, India. In last five years, he has published more than 50 research papers in journals of international repute particularly IEEE Transactions, IETs-UK and Elsevier, Taylor \& Francis and many conference papers. His current research interests include design of switching power converters, high power factor AC/DC converters, hybrid output converters, improved power quality converters for battery charging applications, power quality problems, advanced electric drives and applications of real-time simulator for the control of power converters. He is a member of IEEE and life member of System Society of India.

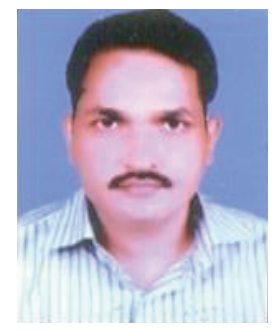

Shambhu N. Sharma received his B.E. degree from the Government College of Engineering, Rewa (M.P.), India in 1994, M.Tech. degree from the Banaras Hindu University (now IIT BHU), UP, India in 2000, and Ph.D. degree from the Delhi University in 2007. Currently, he is working as a Professor in Electrical Engineering Department of the National Institute of Technology, Surat, India. He specialises in the areas of stochastic systems, control theory, stochastic differential equations with applications to electrical and electronic networks. One of his works is known as a pioneering work in stochastic systems. A stochastic system bears his name, the Sharma Parthasarathy stochastic two-body problems. He has published over 20 journal papers in reputed journal, which include International Journal of Control, Automatica, Royal Society Proceedings, Non-linear Dynamics, Journal of the Franklin Institute, AMC etc. He has also published about 12 papers in international conferences and symposia. 